\title{
Mechatronics education: examples in the UK and a proposal in Brazil
}

\author{
G.N. Telles
}

DEMA - FEM UNICAMP, Cidade Universitária "Zeferino Vaz", CP 6122, CEP 13081-970 Campinas, SP, Brazil, Tel. +55 19 239-7966, Fax + 5519 239-3722 (e.mail: geraldo1@fem.unicamp.br)

\author{
P.A. Cauchick Miguel \\ CT - UNIMEP, Rodovia Santa Bárbara-Iracemápolis, Km 1, 13450-000 \\ Sta Bárbara d'Oeste, Brazil - Tel. +5519463 2311, Fax +55194551361
}

T.G. King

Man. \& Mech. Eng., The University of Birmingham, Birmingham B15 2TT, UK - Tel. +44121414 4266,Fax + 441214146800 (e.mail t.king@bham.ac.uk)

\begin{abstract}
This paper describes the structure and contents of a mechatronics engineering course in the State University of Campinas (UNICAMP) in Brazil. Firstly, the paper outlines the UK experience along with two examples of the existing courses there. The second part highlights the reasons for proposing a mechatronics engineering course in Brazil including the required disciplines demanded by the Ministry of Education. In its last part, the paper describes the overall structure of the curriculum, which is a multi-disciplinary effort jointly undertaken by the faculties of Mechanical and Electrical Engineering. Finally, it concludes that the existence of mechatronics engineering courses is an essential step towards the development of a more complete understanding of the challenges of this growing field of engineering.
\end{abstract}

\section{INTRODUCTION}

The word Mechatronics was first used by the Japanese in the late 1970s to describe the philosophy they adopted in design of electro mechanical products to achieve optimum systems performance (Day, 1995). Although there are definitions of Mechatronics there is still considerable debate about what it means (Hewit and King, 1996). It has been formally defined by the European Community as "The synergistic integration of mechanical engineering with electronics and intelligent computer control in the design and manufacture of products and process". A broader definition of mechatronics in the context of machine and product design is (King, 1995): "Mechatronics is the design and manufacture of products and systems possessing both a mechanical functionality and an integrated algorithmic control". Anyway, mechatronics has gained currency in recent years by 
providing a multi-disciplinary approach to engineering design in which a symbiosis of mechanical, electrical, electronic, computer and software engineering is used to create new design solutions to engineering problems. Such innovations vary from development of machine tools, portable video cameras, CD players, and others but it is also applied to process control and measurement technology (Doray. and Bradley, 1994; Milne, 1995).

The adoption of the mechatronics approach through education and training should produce engineers with a wide range of, and perhaps new, skills and attitudes. These professionals should be able to work across the boundaries of engineering disciplines in a true multi-disciplinary approach. Therefore the educational institutions must respond to these challenges, offering mechatronics engineering programmes at undergraduate and postgraduate levels. In recent years, mechatronics has been gaining an increasingly prominent place in higher education all over the world, as evidenced by a number of courses implemented so far. This paper principally details the development of a mechatronics engineering degree in Brazil. It also outlines some experiences in the UK providing a list of existing course as well as some detail of such programmes. The paper concludes with a recognition that mechatronics education is vital to face the new challenges of this growing field of engineering.

\section{MECHATRONICS COURSE - EXPERIENCE IN THE UK}

In recent years, mechatronics engineering has gained a distinguish place in higher education all over the world. This can be seen from the rapidly increasing number of courses offered by higher education institutions in many countries such as Australia (Evans et al., 1995), China (Ye et al., 1995), England (Seneviratne, 1996), Finland (Airila, 1995), Germany (Janocha, 1993), Hong Kong (Venuvinod and Rao, 1994), Japan (Emura, 1995), Russia (Vodovozov, 1995), Scotland Fraser and Milne, 1993), and USA (Rizoni, 1995). More specifically, mechatronics is gaining a prominent place in UK higher education as evidenced by a number of undergraduate and postgraduate taught courses being provided (Hewit and King, 1996). At the present it is estimated that there are around 34 universities and colleges offering degrees and Master's in mechatronics. Table 1, expanded from the work of Acar (1996), summarises courses offered by various institutions in the UK.

The mechatronics engineering programme at the University of Hull serves as a good example of a successful mechatronics curriculum. The department has been active in the field of robots and mechatronics for over 15 years in research as well as education. There are also a wide range of research projects at the Department of Electronics including lasers for assembly of electronic components, virtual reality robot, computer controlled variable-ratio gearbox, and a distributed controller for a six-robot gantry system. The use of novel materials such as magneto-and electro-rheological fluids, ferro fluids, magnetostrictive ceramics and artificial muscles based on chemically actuated polymers are also currently actively investigated. In 1988 the School of Engineering and Computing identified the need for an undergraduate programme to address the topic of mechatronics. A multi-disciplinary approach was created, from which the combined characteristics of computing, electronic, mechanic and human interaction disciplines are developed effectively through a project-based course with additional support of conventional lectures and tutorials. The School is well-equipped with undergraduate laboratory and computer facilities appropriate for mechatronics. There are a number of projects set for the students at different levels, e.g. a mechanical-based project, followed by another which considers software, control, interface and computer control, then a project which is directly related to a industrial problem, and a final year individual project. Recently, the department has been awarded a prize in an undergraduate student robotics project at the Robotix ' 96 Exposition, in Glasgow (see Figure 1). 
Table 1 Mechatronics Undergraduate and Postgraduate Courses in the UK

\begin{tabular}{l}
\hline \multicolumn{1}{c}{ University } \\
\hline Bedford College \\
Blackpool and Fylde College \\
De Monfort University \\
City University \\
Crawley College \\
Falkirk College \\
Glamorgan University \\
Glasgow University \\
John Moores University \\
King's College London \\
Lancaster University \\
Leeds Metropolitan University \\
Loughborough University \\
Manchester Metropolitan Univ. \\
Middlesex University \\
Nottingham Trent University \\
Teesside University \\
University College Warrington \\
University of Abertay Dundee \\
University of Brighton \\
University of Central Lancashire \\
University of Dundee \\
University of Hull \\
University of Leeds \\
University of Surrey \\
University of the West England, Bristol \\
University of Walles College \\
University of Westminster \\
Salford University \\
Sheffield Halam University \\
Staffordshire University \\
Stoke on Trent College \\
Sussex University \\
Swansea Institute of HE \\
\hline
\end{tabular}

$\bullet=$ Existing Programmes.

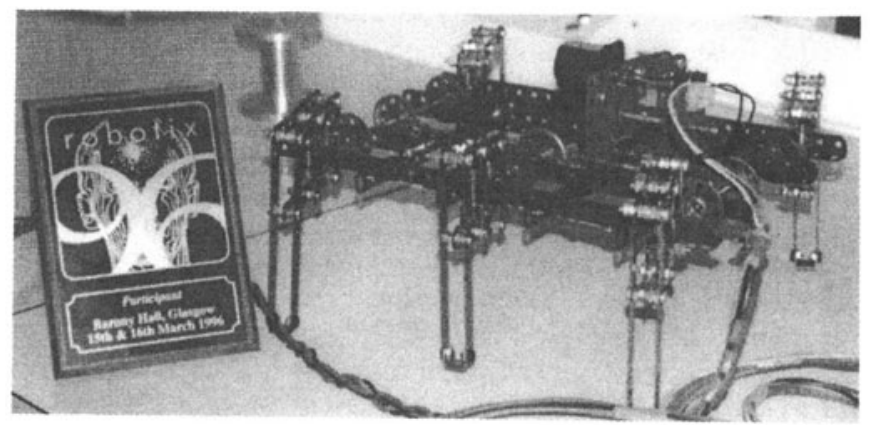

Figure 1 Mechatronics Project Awarded a Prize at Robotix'96. 
Another example of a mechatronics degree in the UK is provided by Manchester Metropolitan University. In fact, two courses are available, a BEng Integrated Engineering Systems and a BEng Mechatronics. These courses were proposed to serve the needs of industry for graduates with wide ranging competence, especially in computer technology and modern techniques applied to manufacturing and process industries. Each of them has different emphasis. The Integrated Engineering Systems degree, as its name suggests, is aimed at systems design and implementation and looks globally at the characteristics of equipment and processes rather than being concerned with detailed design. The mechatronics degree is also concerned with systems, but in particular for automation in the manufacturing industries. There is a great emphasis in this degree on detailed engineering design particularly in areas of robotics and computerised control. Both courses appear to offer good job prospects and meet the general objectives of a broad based engineering degree.

There are not only established but also emerging mechatronics engineering programmes in the UK. For example, Sheffield Hallam University will launch its mechatronics engineering course in the academic year of 96-97. The proposed course has been developed on the basis of a design oriented programme with some specialisation in the final year to allow student to focus on a theme of their choice.

\section{MECHATRONICS INITIATIVES IN BRAZIL}

One of the first mechatronics engineering courses to appear in Brazil in 1988 was in the Polytechnic School (POLI) at the University of São Paulo (USP). The course emphasises systems automation, as the main objective is the integration of mechanical and electronic engineering with computing science. The course was primarily concerned with industrial automation due to a request from the Federation of Industries of the State of São Paulo (FIESP) but now involves aspects of design theory, and bio-engineering (Miyagi, 1996).

The implementation of a mechatronics course described in this paper is being carried out at the Mechanical Engineering Institute (FEM) at the State University of Campinas (UNICAMP). UNICAMP was founded on October 1966, but even within the reality of the Brazilian university setting, where the oldest university has been operating for less than 60 years, UNICAMP may be considered a young institution. Nevertheless, it has already attained a strong tradition in education and technological research. Today, UNICAMP has some 8627 undergraduates in 46 courses, and 6129 enrolled in its 144 graduate level courses (Master's and PhD levels). The Mechanical Engineering Institute is one of the faculties at the UNICAMP. It is divided into seven departments: Computational Mechanics, Energy, Manufacturing Engineering, Materials Engineering, Mechanical Design, Oil Engineering, and Thermal Energy and Fluids.

The basic engineering curriculum of the Mechanical Engineering Institute at the UNICAMP consists of a five year programme. Each year is subdivided into two semesters. The first two years of study are devoted to a basic scientific education; mainly mathematics, physics, chemistry, material engineering, engineering design, and some laboratory activities. However, even considering the success of its traditional mechanical engineering course, the necessity of development of a multi-disciplinary approach to engineering has started to gain academic and industrial acceptance. Consequently, it has been decided to propose a mechatronics engineering programme.

Looking into the activities performed by a professional in the field of mechatronics two relevant areas were be highlighted (Altemani et al., 1996): the conception, design, and operation of automated production systems, and the design and manufacturing of automated systems involving software and hardware engineering. Considering these areas, in 1994, the Brazilian Ministry of Education defined the disciplines required for a mechatronics engineering programme, namely: 
Process Control, Industrial Systems, Instrumentation, Discrete Mathematics for Automation, Industrial Computing Science, Manufacturing Management, Systems Integration and Assessment.

It is quite clear that these disciplines require a strong integration between mechanical, electrical engineering and computing science in order to propose a undergraduate course in mechatronics. In the beginning of 1995 , a committee was formed to elaborate a proposal for a mechatronics engineering degree, described below.

\subsection{Structure of Mechatronics Engineering at FEM-UNICAMP}

There are various factors which justify the implementation of a mechatronics engineering course at FEM-UNIC(Altemani et al., 1996). After extensive discussion, the committee has identified some needs and requirements for a mechatronics engineering curriculum. The curriculum structure should involve, of course, the disciplines required by the Ministry of Education as well as a large number of subjects incorporating laboratory activities, i.e. 'hands-on' experience (correspondent to $20 \%$ of the total number of hours). It is worth noting that the laboratory activities were scheduled after the corresponding taught disciplines in order to have a theoretical foundation for them. Furthermore, a balance between the disciplines of mechanical, electrical engineering and computing science should be achieved considering that the basis of this programme should be in mechanical engineering. Another interesting aspect is the effort to allocate technical disciplines in the early semester to enthuse the students right from the beginning of the course. The course structure along with the proposed disciplines can be seen in Table 2 at the end of this paper. These disciplines have, on average, three hours per week.

Figure 2 shows the distribution of the disciplines by area. Note that some of the areas shown in Figure 2 (Biology, Chemistry, Energy, etc.) are demanded by the Ministry of Education for any engineering course in Brazil. It can be seen that the course has a strong orientation towards design, computing science, electronics engineering, and manufacturing processes. The proposed programme is to be launched at the beginning of the 1998 academic year, with an initial intake of 50 students per annum.

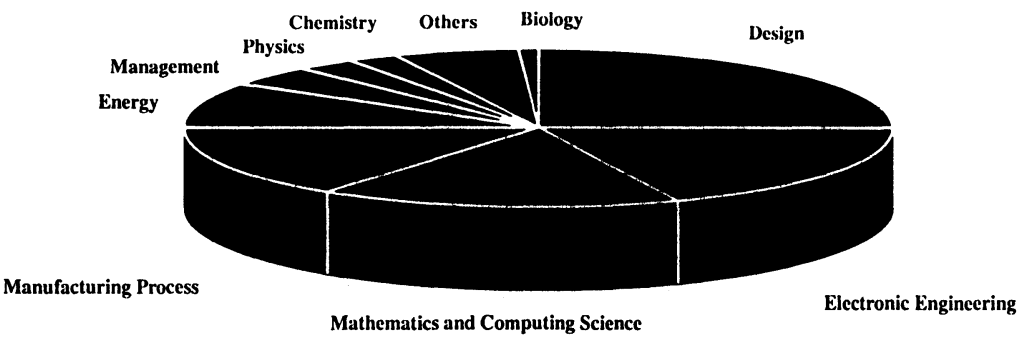

Figure 2 Distribution of Areas in the Mechatronics Programme.

\section{CONCLUSIONS}

In recent years there are changes in industry to more integrated production especially with the introduction of advanced manufacturing technologies (e.g. FMS and CIM) in addition to new design philosophies to obtain the best possible solution to products or processes. Design of such products or process must, therefore, consider multi-disciplinary approaches. Undoubtedly mechatronics engineering solutions are the key factor to achieve such goals. However, the present driving force for further development of mechatronics must embrace the need of an engineer working in a hybrid 
environment involving mechanics, electronics and computing. In response to these challenges the educational system must adapt to this new reality. Education establishment have been developing courses aimed at producing the technologically aware engineers for the next century. It is believed that these programmes must consider:

- Activities based on team working and case studies.

- Balance between taught courses and project based learning.

- Design based projects and hands on experience in problems solving.

- Ability to plan and apply a mechatronic approach to a technological problem.

It has been shown that the aspects of a mechatronics approach to education must involve the previous statements. The results of such an approach should bring many benefits for both industry and academia. This paper has highlighted the importance of mechatronics education. It listed mechatronics programmes currently applied in the UK and described the philosophy, structure and contents of a mechatronics engineering degree in Brazil. The aim of such a development is to build a more complete understanding of this growing field of engineering.

\section{ACKNOWLEDGEMENTS}

The authors would like to express their appreciation to the committee members of the mechatronics engineering course, Dr C. Altemani, Dr A. Diniz, Dr E. Nóbrega, and Dr S. Button of the Mechanical Eng. Institute (FEM), and to Dr M. Andrade Neto of the School of Electrical and Computing Eng. (FEE), all of them from the State University of Campinas (UNICAMP). Thanks are also due to Dr K. Selke, of the University of Hull, and Mr A. Verwer from Manchester Metropolitan University, both from the UK, who helped in offering an informative visit to their department. The authors would like to thank Dr K. Dutton, from Sheffield Hallam University, UK, and to Dr P. Miyagi from USP, Brazil, for providing useful information about their mechatronics courses. Additional thanks to Prof. R. Parkin of Loughborough University for helpful discussion concerning mechatronics education.

\section{REFERENCES}

Acar, M. How Does the Higher Education World Respond to the Mechatronics Challenge (1996).

Colloquium on Mechatronics in Education, Institute of Electrical Eng., Manchester.

Airila, M. Ten Years of Mechatronics Education at Helsinki University of Technology (1995).

Int. Conference on Recent Advances in Mechatronics, 266-271, Istanbul, Turkey.

Altemani, C.A.C., Diniz, A.E., Nobrega, E.G.O., Telles, G.N., Andrade Neto, M., Button, S.T. (1995) Undergraduate Course on Mechatronic Eng., FEM, UNICAMP.

Day, C.C. The Mechatronic Manufacturing Solution - Myth or Panacea (1995). International Conference on Recent Advances in Machatronics, Istanbul, Turkey, 259-265.

Dorey, A.P. and Bradley, D.A. (1994) Measurement Science and Technology - Essential Fundamentals of Mechatronics. Measurement and Science Technology, 5, 1415-1428, 1994.

Emura, T. Mechatronic Education and Research at Tohoku University (1995). International Conference on Recent Advances in Mechatronics, 255-265, Istanbul, Turkey.

Evans, B.J., Shahri, A.M., Naghdy, F. and Cook, C.D. (1995) Developing a Mechatronics Laboratory at the University of Wollongong. Second International Conference on Mechatronics and Machine Vision in Practice, 315-319, Hong Kong. 
Fraser, C.J., Milne, J.S. and Logan, G.M. (1993) An Education Perspective on Applied Mechatronics. Mechatronics, 3(1), 49-57.

Hewit, J.R. and King, T.G. (1996) Mechatronics Design for Product Enhancement. IEEE/ASME Transaction on Mechatronics, 1(2), 111-119.

Janocha, H. (1993).Mechatronics from the Point of View of Geman Universities. Mechatronics, 3(5), 543-558.

King, T.G. (1995) Millrights to Mechatronics: The Merits of Multi-disciplinary Engineering. Mechatronics, 5(2/3), 95-115.

Milne, J. (1995) Mechatronics: An Integrative Approach. Manufacturing Engineer, 159-162.

Miyagi, P. (1996) Mechatronics Engineering at the POLI-USP. Private Communication.

Rizzoni, G. (1995) Development of a Mechatronics Curriculum at the Ohio State University. Proc ASME International Mechanical Engineering Congress \& Exposition, San Francisco, 1-4.

Seneviratne, L. (1996) Mechatronics at King's College London. Colloquium on Mechatronics in Education, Institute of Electrical Engineering, Manchester.

Venuvinod, P.K. and Rao, K.P. (1994) A Mechatronic Engineering Degree Course to Meet the Needs of Hong Kong. Proc. of Mechatronics and Machine Vision in Practice Conf., 52-57, Toowoomba, Australia.

Vodovozov, V.M. (1995) The Educational Resources of Mechatronics. Mechatronics, 5(1), 15-24.

Ye, Z.Q., Xun, L.B. and Tse, P.W. (1995) Development of Mechatronic Engineering in the Special Economic Zone, Shenzhen, China. Proc. of the 2nd Int. Conference on Mechatronics and Machine Vision in Practice, 331-332, Hong Kong.

\section{BIOGRAPHY}

\section{Geraldo N. Telles}

Dr Geraldo Telles graduated in Mechanical Engineering at the State University of Campinas (UNICAMP), Brazil, in 1971. He then worked as a research engineer at the Technology Centre at UNICAMP, Nardini Machine Tools Company, and at the Centre for Computing Science of the Ministry of Science and Technology. Dr Telles obtained his $\mathrm{PhD}$ in 1990 and became a senior lecturer in the Mechanical Engineering Institute at UNICAMP. At present he is Associate Professor and his research activities involve CAD/CAM systems (interface development), CNC machines (simulators and automatic programming), industrial robots, FMS, and CAPP (features strategies).

\section{Paulo A. Cauchick Miguel}

Dr Paulo Miguel graduated in Industrial Engineering at the Methodist University of Piracicaba (UNIMEP), Brazil, in 1986. He then worked as a manufacturing engineer for Allied Automotive and Varga companies until 1990 when he became a lecturer at the UNIMEP. In October 1993 he moved to the University of Birmingham, UK, to join the Mechatronics group in the School of Manufacturing and Mechanical Engineering. His research activities include quality and metrology developments, and engineering education. Dr Paulo Miguel completed his $\mathrm{PhD}$ in December 1996.

\section{Tim G. King}

Professor Tim King BSc (Eng), MDes RCA, PhD, FRSA is Professor of Mechanical Engineering at the University of Birmingham where he heads the Mechatronics Research Group in the School of Man. and Mech. Eng. His current research includes development of ultra-high speed piezoelectric actuators, piezoelectric motors, calibration techniques for surface metrology and CMM applications, and microprocessor and DSP based systems for computer-visual inspection and controls of deformable patterned materials. He is author of over 90 journal and conference papers. 


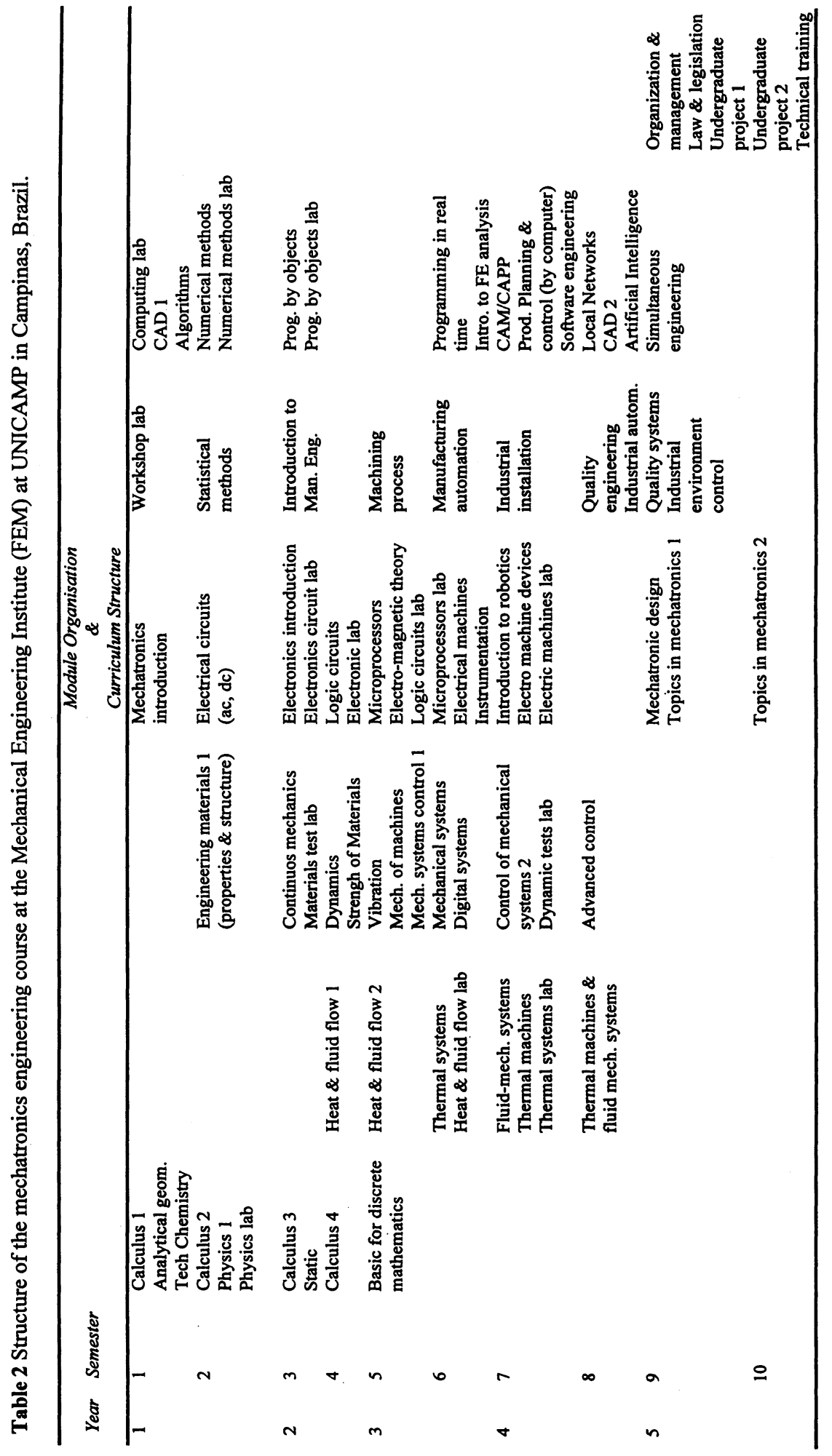

